L Lawrence Berkeley Laboratory UNIVERSITY OF CALIFORNIA
Accelerator \& Fusion Research Division
LBL -19527
DE85 015561

Presented at the 1985 particle Accelerator Conference, Vancouver, B.C., Canada, Hay 13-16, 2985

TAE EPFECT, OF FOCOSING PIELD WONLINEARITIES IN MBE-4 ON YRANSUERSE BEAY DYNAMICS!

C.M. Celata, V.O. Brady, L.J. Laslett and L. Smith

May 1985

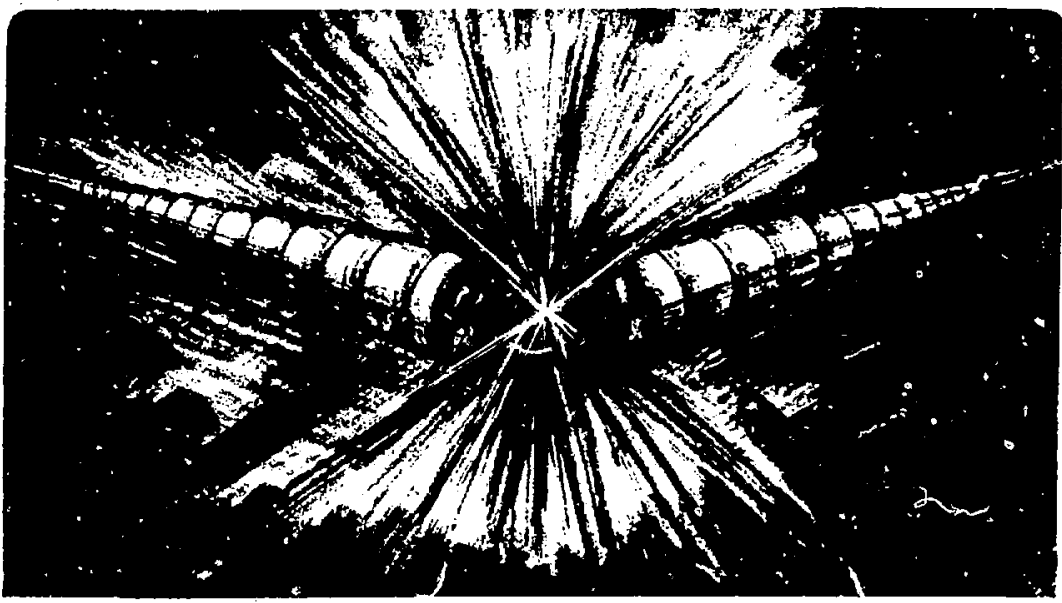


LBL- 19527

HIFAN-283

\title{
THE EFFECT OF FOCUSING FIELD NONLINEARITIES IN MBE-4 ON TRANSVERSE BEAM DYNAMICS*
}

\author{
C.M. Celata, V.O. Brady, L.J. Laslett, L. Smith \\ Lawrence Berkeley Laboratory \\ University of California \\ Berkeley, CA 94720
}

\author{
I. Haber \\ Naval Research Laboratory \\ Washington; DC 20375
}

\section{May 1985}

\section{DIGCLAIMER}

\begin{abstract}
This report was prepared as an account of wark sponsoted by an agency of the United Siates Government. Neither the United States Government nor any agency therewf, nor any of their employees, makes any warranty, express or implied, or assumes any legal liability or tesponsibility for the accuracy, completeness, or usefulness of any information, apparatus, proiuct, or process disclosed, or represents that its use would not infringe privately owned rights. Reference herein to any specific commercial product, process, or service by trade name trademark, manufacturer, or otherwise does not necessarily constitute or imply its endorsemen1, recommendation, or favoring by the United States Goverament or any agency theresf. The vitws and opinions of authors expressed herein do not necessarily state or reflect those of the United States Government or any agency thertof.
\end{abstract}

"This was supported by the Office of Energy Research, Office of Basic Energy Sciences, U.S. Department. of Energy under Contract DE-ACO3-76SF00098. 


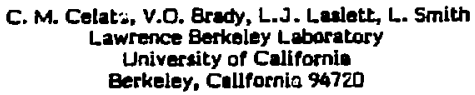

1. Haber

Naval Revearch Laboratory

Washington, DC 20375

\section{Abstract}

A particle simulation code was used to study the effect on transverse beam dynamics of nonlinearities of the focusing fleld in a linear accelerator transporting a multiple beam array. Nonlinear field strengths for various multiple-beam degign geometries were calculated by relaxation codes for use in the simulation calculation. Nonlinearities dus to asymmetry of the electrode array with respect to a single beam were found to be nogllgible. Electrode end effect nonlinearities led to emittance growth for off-axis boams, though for the geometry of MBE-4, this was negligible. For nisaligned beams, a dodecapole fleid caused significent emittance growth. This was not seen in single particle tracking calculations. Fields due to induced charge on the electrodes can reduce this effect, or the oodecapole field can be eliminated by proper choice of the alectrode radius.

\section{Introduction}

An array of quadrupoles can be used to transport multiple charged particic beams through a linear accelerator. The geornelsy of one such array, that of the 4 beam Mulciple Beam Exfariment (MAE-4) presently under construction at Lawrence Berkeley Laboratory, is shown in Fig. 1. This expariment will accelerate high current heavy ion beams through an alternating gradient electrostatic focusing system. 2 We examine here the effect of focusing field nonlinearities on the transverse dynamics of the transported beams. Such field nonlinearitles result from a

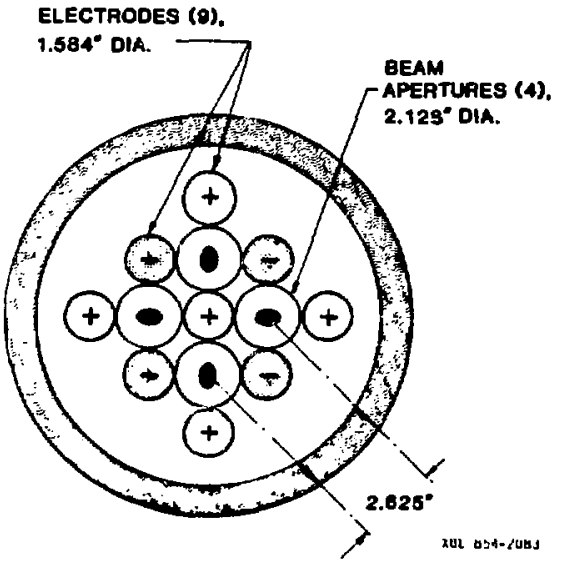

Fig. 1. iransverse cross section of the MBE-4 experiment. variety of sources of field error. Those atudied here can be divicied into three clases: (1) imperfections in the field of a single quadrupole, (2) nonlinearities due to the asymmetry of the complete electrode array with resect to the beam of interest, and (3) end effects of the quedrupolea.

Of particular Intorest is the effect of the: nonlinearities on the space-charge-dominated beams neaded to transport the required power for havy ion fusion applications. Therefore jeam stabllity has ban explared using a twu-dimenaional (tranaveres plene) pexticle-in-call (PIC) cunputer simulation cods, as well as an "envelope-type" code, which trecks single particles through the potential of the besm, generated (nca-welf-condittently) by an integration of the KV envelope equatlont?

\section{Imperfections of the Pupdrugole Field}

The focusing fleld potential cen In general bo wrikten as a sum of multipoles:

$$
v(r, \theta)=v_{0} \sum_{n=1}^{\infty}\left[A_{n}\left(\frac{r}{d}\right)^{m} \cos \omega+B_{n}\left(\frac{r}{d}\right)^{m} \sin m\right] \text {, }
$$

where $r$ and 9 are polar coordinates about an origin at the center of a focusing channel; it, the aperture redlus, is the distance to the surface of the neareat focualing electrocied; and $\theta$ is mosaured from the $x$ axis, whlcti pases through the orlgin and the center of one of thes: electrodes. We consider in this sectson only the field of the single quadrupole centered at the origiz. Asuming that the four-fold quadrupole symmetry is meintained, we find that $B_{m}=0$ for all $m_{\text {, }}$ and $A_{m}=0$ unless $n=4 n+2$, with $n=0,1,2 \ldots \ldots$. Noglecting the terms for $n>1$, since it is feasible in practice to make the electrodes unch that these high order terms are completely nogllgible, we find that the nonlinearity of concern is due tr a dodecapole potential: $V-V_{0} A_{6}(r / d)^{6} \cos 6 \theta$. If $R$ is chosen to havo the value $1.145 i d^{6}$ - $R_{0}$, where $R$ is the electrode radius, then $A_{6}=0.4$ However it may be of interget to ctrange this ratio for a number of reasonk, e.g., to increate the aperture size, of to decrease the trangverse dimensions of the marhine.

The PIC code wa used to deiermine the stabillty of a high ourrent lon beem to the dodecapole fleld. In tha code, the quadtupole focusing force was applied uning a thin tens approximation. Consistent with this, the dodecapole was also spplied as a momentum kick to each particle at the axial position of the centcr of eash lens -- i.e., once per lattlce half-period. The relaxation code POIS50N was used to datermine $\boldsymbol{A}_{6}$ for aiven $R$. The simulation boundary cinditions were periodic in $x$ and $y$, but the beam was kept far enough frum the calculatlon boundarles that it did not Interact with it: perlodic Imagos. The bonm was token to bo uniform in dentity and julptical in chepa, with radil mitched to the focusit is system using a KV envelope cods. The velocity ditutibution was Maxwellian, with a uniform temperature throughout the beam. No acceleration wa applied, and it was ascumed that $v / c \ll 1$. 


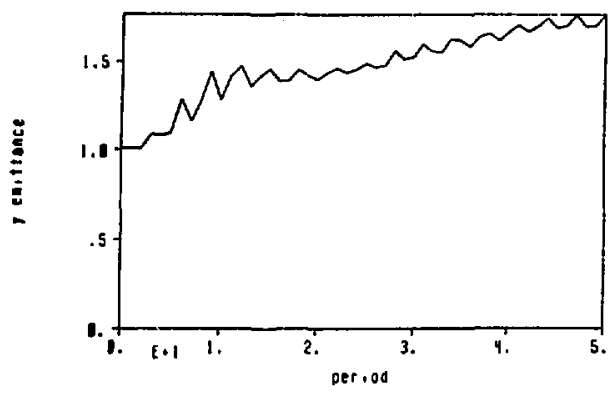

an-m)

Fig. 2. y rms emittence (normalized to its initial value) vs. 2 , with a dodecapole force acting. Parameters are given in the text. $a=11 \mathrm{~mm}$.

The simulation showed no effect of the dodecepole on the beam when the beam was centered on the axis of the transport channel. For misaligned beama, however, emittance growth accurred in both the $x$ and $y$ dimensions. Figure 2 demonstrates this effect. Here R/d was chosen to be 0.573 , giving a value of $A_{6}=5.777 \times 10^{-2}$. The beam major radius was a $=0.523 \mathrm{~d}$, with $\sigma=12^{\circ}$, $\sigma_{0}=60^{\circ}$ (where a and of are the particle phase advance per lattice period with and without the space charge force), and an initlal offect of the baam centroid of $A x-a / 2$ at the center of a focusing lens. The rms emittance grows, and accompanying the growth be an aselllation of the emittance with frequency slightly greatar than the coherent betation frequency. The growth ls linear for $\sim 10$ poriods, then slow: or enturates, and subequently grows again linearly, but with reduced growth rate. Single particle celculations, using the code mentioned above, show no sign of developing atochaticity for tha same nonlinearity strength.

To study the effect of the dodecapole a seites of simulation runs was done for beama whose centroids were offset in the $x$ diection. The rewits suggest that the rms emittance growth is roughly proportional to the emittance oscillation amplitude. The growths of emittance in $x$ and y are comparable. As the emittance grows, the amplitude of the centroid motion damps (by $\sim 5 \%$ for the case shown in Fig. 2). The oscillation amplitude appears to be linearly proportional to $A_{6} h$, where $h$ is the amplitude of the centroid misalignment. It increases with increasing beam radlus or of or decreasing a. Phase plots suggest the cccurrence of an even mode of oscillation as the dominant mode (see Figs. 3,4), perhapa the $j=0$, n $=4$ mode. 5 in the beam frame the dodecapole potentlal has an octupole component whose magnitude is proportional to $h^{2} \cos \omega^{t}$, where $\omega_{c}$ is the coherent betatron frequency. This comporvent may be driving the $\mathrm{J}=0, \quad=4$ mode, whose potential $\left(-r^{4} \cos 40\right.$ ) is of the same form, and whose frequency is close to the coherent betatron frequency for low ofos.

The emiteance growth due to this mode gives a limit on the acceptable alignment for the accelerator, given the current density one desires to transport. The effect can be reduced, of course, by setting the ratio R/d to reduce the strength of the dodecapole force. We have also found, however. that the effect of the "image force" due to induced churge on the electrodes is to suppress the emittance growth due to the dodecapole. This ef fect is also diecused in another paper at this conference. 6 The ratio of $R / d=0.744$ used in MBE-4 was chosen because for this goometry the simulation predicts that the image force
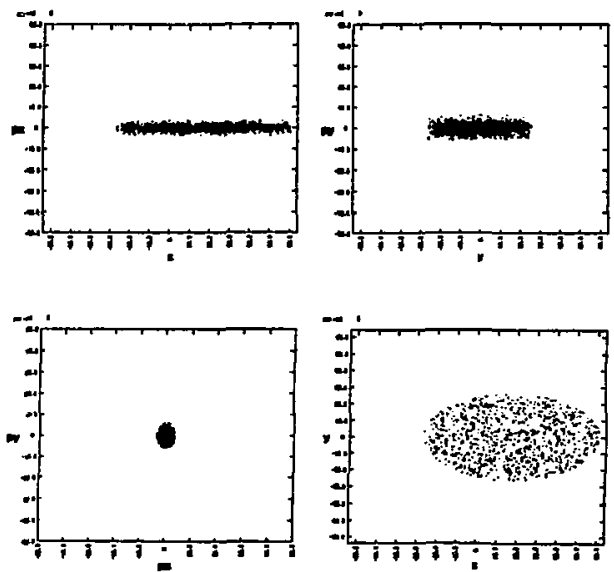

n. sterks

Fig. 3. Phase apace, momentum and density plote for beam at the initialization of the simulation. Parameters are those of Flg. 2, with $a=14.1 \mathrm{~mm}$.
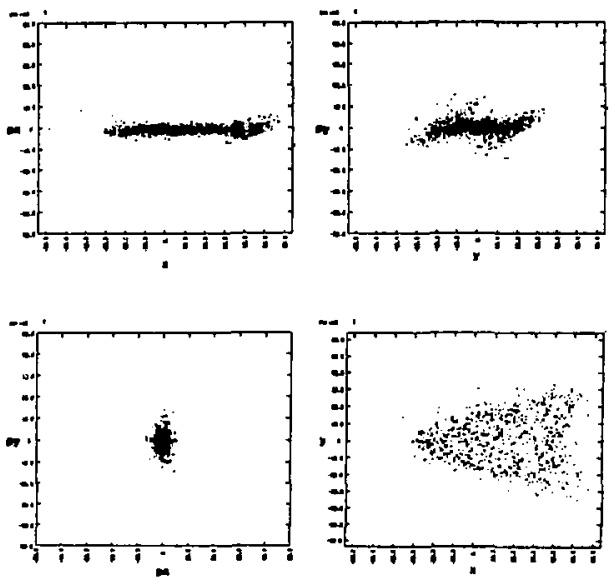

14. as4-2374

Flg. 4. Phase space momenusm, and configuration plots at Period 7 for the parameters of Fig. 2, with $a=14.1 \mathrm{~mm}$.

suppresses emittance growth due to the dodecapole, and vice versa.

\section{Asymmetry Nonlinearities}

We next consider nonlinearities which occur due to the asymmetry of the complete electrode array with respect to a single beam. The code POISSON was used to calculate 
the strength of the coefficients $A_{m}$ and $B_{n}$ for the potentiel du to the electrode array of MBE-a. The electrode array was urrounded by a groundad cylinder at redius $R c / d=5.05$ and $R / d=0.744$, as in $M a E-A$, ind the electrodes were at potentials of $-V$ and 0 . Rewitu showed that, except for the dadocapole component diccuseced in Section 2, all nonlinear forces except the dipole were $<1 \%$ of the quidrupole farce, for $r<d$. This was aseumed to be negligible, and no simulation code studies were done.

The dipole term provides a force which dieplaces the equilibrium position of the beam. The dipole strength calculated would dtsplace the beam by approximidely $0.35 \mathrm{~mm}$.

Similar calculations were done with the electrode centers at the same positions as in MBE-4, but with larger $R$, so that $R / d=1.1457$. In this case for $r<d$ and $n>2$ all nonlinaar forces were less than $0.06 \%$ of the quadrupole force. The beam displacement due to the dipole force was 7 wr. This configuration therefore shows much less nonlinearity than the version with the smaller electrode radius (and therefore larger aperture) discussed above. This is due to the greater shielding of the beam by the electrodes of its focusing channel. Howover, nelther geonetry appears to present nonlinearity of sufficient strength to cause collective oscillationg of the beam or significant beam misalignment.

\section{End Effects}

In order to study quadrupole end effects, a 3-D relaxation code was used to determine the multipole expansion of the associated nonlinearlty. The fringe fleld was found to conslst mainly of an octupole component, with a $z$ dependence aboi $\cdot s$, the center of the lena which was odd in z. (The force is defocusing at the entrance to a focusing lens.) This was applied in the simulation as momentum kicks of alternating sign one eighth of attice period before and after each lens, approximating an occupancy factor of 0.5 . The strength of the kick was determined by the integration over $z$ of the octupole component of the fringe field as calculated by the relaxation code, and therefore was of the form $\quad V=V_{E} A_{4}^{\prime}(r / d)^{4} d(z) \cos 4 \theta$, where the potentials at the quadrupoles were $\pm V_{f}$. For $R=R_{0}=1$ inch and half periods of 6,9 , and 12.5 inches, the values of $A^{\circ}$ were $1.7 \times 10^{-3} \mathrm{~m}^{-1}, 1.8 \times 10^{-3} \mathrm{~m}^{-1}$, and $1.9 \times 10^{-3} \mathrm{~m}^{-1}$, tespectively.

The simulation showed no change in the oeam for the nonlinearity strengths calculated for MBE-4, which has a half-period of 9 inches. For values of $A_{4}{ }^{\prime}$ approximately twice as large, an oscillation of the rms emittance was seen, which was approximately $5 \%$ for a beam misalignment of $5 \mathrm{~mm}$. For higher nonlinearity strengths, for misallgned beams, some rms emittance growth occurred in beams with low o, along with an oscillation of the emittance. An example is shown in Fig. 5. ( $h_{4}$ ' for this figure is 6.4 times its value for MBE -4.) The emittance growth increased with $A_{4}{ }^{\prime}$ and the misalignment magnitude, and decreased with increasing $a / o_{0}$. The $\mathrm{rms}$ momenta increased, whlle the ims beam radii remained approximately constant. As with the dodecapole nonlinearity discussed above and the image porce nonlineariky discussed elsewhere, 6 the oscillation of the rms emittance occurred at a frequericy of approximately twice the coherent betation frequtincy. As the rms emittance grew, the amplitude of tre coherent betatron oscillation increased - - by approximately $25 \%$ for the case shown in Fig. 5 . This occurred for the MBE-4 design paraneters also, but was of negligible magnitude for the 30 lattice period length of the experimient.

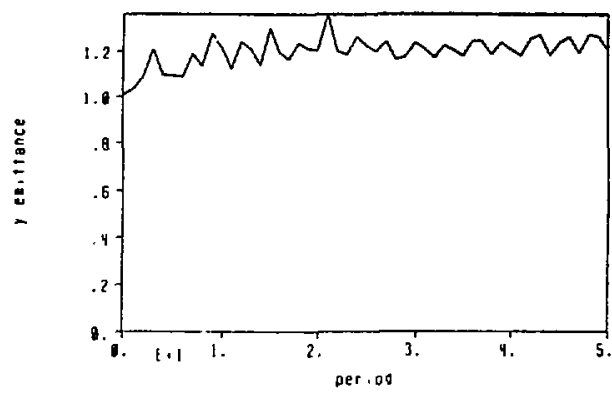

14 $44+2219$

Fig. 5. y emittance (normalized to its inithal value) vs. 2 for $A_{4}^{\prime}=1.16 \times 10^{-2} \mathrm{~m}^{-1}, \quad \sigma_{0}=60^{\circ}, \quad \sigma=12^{\circ}$, $a=11 \mathrm{~mm}, h=5 \mathrm{~mm}, \theta=45 \%$.

\section{Summiex}

A particle simulation code has been uasd to study the tranoverse dynamics of a space-charge dominated beam in the presence of varlous focusing field nonlinearlties. A dodecapole potentlal was found to cause an osclllation and growth of the rms emittance for misallgned beams and low partlcle phase advance, though the simulation predicte that in MBE-4 thls will be suppressed by lmage forces. Nonlinearlty due to the asymmetry of the electrode array as seen by a single beam was calculated to be of negligible magnitude. Finally, quadrupole end effects caused no signiflcant beam changes for the parameters of the MBE-4 experiment, but appear to amplify coherent betatron motion and lead to rms emittance growth for much higher nonlinearity strengths and longet accelerators.

\section{References}

(1] A.W. Maschke, "Meqalac A New Approach to Low Beta Acceleration," BNL 51029, UC-28, 1 June 1979.

[2] R.T. Avery et al., "MBE-4, A Heavy Ion Multiple-Beam Experiment," also at thls conference.

[3] I.M. Kapchinskij and V.V. Vladimirsklj, Proc. 1959 Internat. Conf. High Energy Accelerators, p. 274 (CERN, Geneva, Switzerland; 1959).

[4] I.E. Dayton, C. Shoemaker, and R.F. Mozley, Roy, Sci. Inst., 25, 488 (1954).

[5] R.L. Gluckstern, Proc. 1970 Nat. Accelerator Lab. Linear Accelerator Conf. (M.R. Tracy, Ed.), vol. 2. p. II I (FNAL, Batavia, Ill., 1970).

[6] C.M. Celata, L. Haber, L.J. Laslett, L. Smith, and M.C. Tiefenback, The Effect of Induced Charge at Boundaries on Transverse Dynamles of a Space-Charge-Dominated Beam, also at this conference. 
This report was done with support from the Department of Energy. Any conclusions or opinions expressed in this report represent solely those of the author(s) and not necessarily those of The Regents of the University of California, the Lawrence Berkeley Laboratory or the Departmenl of Energy.

Reference to a company or product rame does not imply approval or recommendation of the product by the University of California or the U.S. Department of Energy to the exclusion of others that may be suitable. 